\title{
Oxidation Behavior of Matrix Graphite and Its Effect on Compressive Strength
}

\author{
Xiangwen Zhou, ${ }^{1}$ Cristian I. Contescu, ${ }^{2}$ Xi Zhao, ${ }^{1}$ Zhenming Lu, ${ }^{1}$ Jie Zhang, ${ }^{1}$ Yutai Katoh, \\ Yanli Wang, ${ }^{2}$ Bing Liu, ${ }^{1}$ Yaping Tang, ${ }^{1}$ and Chunhe Tang ${ }^{1}$ \\ ${ }^{1}$ Institute of Nuclear and New Energy Technology of Tsinghua University, Collaborative Innovation Center of \\ Advanced Nuclear Energy Technology, The Key Laboratory of Advanced Reactor Engineering and Safety, Ministry of Education, \\ Beijing 100084, China \\ ${ }^{2}$ Oak Ridge National Laboratory, UT-Battelle Inc., P.O. Box 2008, Oak Ridge, TN 37831, USA
}

Correspondence should be addressed to Xiangwen Zhou; xiangwen@tsinghua.edu.cn

Received 22 December 2016; Revised 15 June 2017; Accepted 4 July 2017; Published 1 August 2017

Academic Editor: Eugenijus Ušpuras

Copyright (c) 2017 Xiangwen Zhou et al. This is an open access article distributed under the Creative Commons Attribution License, which permits unrestricted use, distribution, and reproduction in any medium, provided the original work is properly cited.

\begin{abstract}
Matrix graphite (MG) with incompletely graphitized binder used in high-temperature gas-cooled reactors (HTGRs) is commonly suspected to exhibit lower oxidation resistance in air. In order to reveal the oxidation performance, the oxidation behavior of newly developed A3-3 MG at the temperature range from 500 to $950^{\circ} \mathrm{C}$ in air was studied and the effect of oxidation on the compressive strength of oxidized MG specimens was characterized. Results show that temperature has a significant influence on the oxidation behavior of MG. The transition temperature between Regimes I and II is $\sim 700^{\circ} \mathrm{C}$ and the activation energy $\left(E_{a}\right)$ in Regime I is around $185 \mathrm{~kJ} / \mathrm{mol}$, a little lower than that of nuclear graphite, which indicates MG is more vulnerable to oxidation. Oxidation at $550^{\circ} \mathrm{C}$ causes more damage to compressive strength of MG than oxidation at $900^{\circ} \mathrm{C}$. Comparing with the strength of pristine MG specimens, the rate of compressive strength loss is $77.3 \%$ after oxidation at $550^{\circ} \mathrm{C}$ and only $12.5 \%$ for oxidation at $900^{\circ} \mathrm{C}$. Microstructure images of SEM and porosity measurement by Mercury Porosimetry indicate that the significant compressive strength loss of $\mathrm{MG}$ oxidized at $550^{\circ} \mathrm{C}$ may be attributed to both the uniform pore formation throughout the bulk and the preferential oxidation of the binder.
\end{abstract}

\section{Introduction}

Graphite offers numerous advantages for in-core nuclear applications because of its thermomechanical properties and chemical inertness in nonoxidizing environments. Therefore, it is widely used in HTGRs as the moderating, reflector, structural, and fuel element matrix materials [1-3]. However, graphite is easily oxidized by air at temperatures greater than $450^{\circ} \mathrm{C}$ [4]. In low probability, yet imaginable off-normal events, air or water ingress accidents would cause fast graphite corrosion that may affect the core and fuel integrity in HTGRs. Many studies related to the oxidation behavior and its impact on the mechanical properties of nuclear graphite materials have been reported in recent years [5-8]. Contescu [8] studied the effect of the oxidation temperature on the compressive strength of PCEA graphite. Samples in the direction of grain were oxidized in air at two temperatures (600 and $700^{\circ} \mathrm{C}$ ) and three levels of weight loss. Results showed that oxidation at $600^{\circ} \mathrm{C}$ was more damaging on strength than oxidation at $700^{\circ} \mathrm{C}$, at comparable levels of weight loss which was due to the differences in the distribution of oxidation layer and mechanism of development of porosity. Whereas a block reactor core consists mainly of highly graphitized nuclear graphite and contains only a small amount of fuel element matrix graphite (MG); the active pebble-bed core consists of a large part of fuel element matrix graphite [9]. The MG contains around $10 \%$ of incompletely graphitized resin-derived carbon because of temperature limit restriction $\left(<2000^{\circ} \mathrm{C}\right)$ during the fabrication process of pebble fuel elements [3]. Because of its incompletely graphitized binder content, the activation energy of historic matrix-grade graphitic materials is lower than that of most modern nuclear graphite [9-12]. The activation energies of filler and binder for A3-27 were reported separately by Moormann et al. [9] 
The activation energy of the filler $(165 \mathrm{~kJ} / \mathrm{mol})$ is larger than that of the binder $(123 \mathrm{~kJ} / \mathrm{mol})$. Lee et al. studied the oxidation rate of graphitic matrix material GKrS produced by ORNL thermogravimetrically with temperatures from 873 to $1873 \mathrm{~K}$ [10]. The activation energy for GKrS was determined to be $111.5 \mathrm{~kJ} / \mathrm{mol}$ in the kinetic regime, from 873 to $1023 \mathrm{~K}$. It is supposed that the lower activation energy of GKrS matrix graphite could be attributed to the preferential oxidation of the binder phase in the kinetic regime [10]. Many researchers have observed the preferential binder oxidation in their studies as well [11-13]. The preferential oxidation of binder often has a significant influence on the degradation of mechanical properties of graphite in the kinetic regime of graphite oxidation that may lead to severe consequences such as failure of pebble fuel elements and subsequent release of large amounts of radioactive fission products. Comparing with the large amount of reported researches on the oxidation behavior of nuclear graphite, oxidation experiments and basic kinetic data for matrix-grade graphite in air are sparse because the historic grades of A3-3 or A3-27 from Germany are no longer commercially available and modern candidate grades are still being developed and difficult to obtain [10]. In this study, the A3-3 MG composing approximately 71\% natural flake graphite, $18 \%$ artificial graphite, and $11 \%$ phenol resin was newly developed and manufactured in INET, Tsinghua University of Beijing, China [3]. Chinese domestic producers produced all the raw materials used in the preparation of the newly developed A3-3 MG. The oxidation performance of the MG is very crucial for the integrity evaluation and safety analysis of pebble fuel elements in normal and off-normal conditions. In order to reveal the oxidation performance of the MG, the oxidation behavior of $M G$ in air in the temperature range from $500^{\circ} \mathrm{C}$ to $950^{\circ} \mathrm{C}$ was studied, and the effect of oxidation at two typical temperatures on the compressive strength of MG was characterized.

\section{Experimental}

2.1. MG Specimens. All MG specimens covered by this report were machined from the MG pebbles manufactured by the Institute of Nuclear and New Energy Technology (INET) [3]. In order to meet the specimen requirements of standard test method for compressive strength of carbon and graphite (ASTM C-695) [14], a compromise had to be made to machine the specimens into cylindrical shape with $2: 1$ ratio between length $(25.4 \mathrm{~mm})$ and diameter $(12.7 \mathrm{~mm})$. This exceeds the recommended minimum specimen size of $9.5 \mathrm{~mm}$ diameter and $19 \mathrm{~mm}$ length for compressive strength test. Meanwhile, as the maximum grain size in $\mathrm{MG}$ is $0.16 \mathrm{~mm}$, the specimens with diameter of $12.7 \mathrm{~mm}$ were in compliance with the requirement that the diameter of test specimens for compressive strength measurements should be at least five times larger than the maximum grain size in graphite. As shown in Figure 1, 6 specimens were machined from a MG pebble, in parallel orientation to the molding direction during fabrication. Five pebbles were used to machine 30 cylindrical specimens. The machined specimens were then heat-treated at $1900^{\circ} \mathrm{C}$ in vacuum for 2 hours to remove any trace of metallic impurities that might be
TABLE 1: Physical properties of specimens before oxidation.

\begin{tabular}{lcccc}
\hline & Length $(\mathrm{mm})$ & Diameter $(\mathrm{mm})$ & Weight $(\mathrm{g})$ & $\begin{array}{c}\text { Density } \\
\left(\mathrm{g} / \mathrm{cm}^{3}\right)\end{array}$ \\
\hline Average & 25.308 & 12.627 & 5.506 & 1.737 \\
St. dev. & 0.033 & 0.023 & 0.032 & 0.004 \\
\hline
\end{tabular}

introduced during machining. Then the specimens were supersonically cleaned with acetone and ethanol and dried at $120^{\circ} \mathrm{C}$ for 24 hours. Physical measurements showed that the specimens were uniform. The average dimension and density values with standard deviation of these specimens before oxidation are shown in Table 1.

2.2. Oxidation Measurements. The MG specimens were oxidized in air using the protocol recommended by ASTM D7542-09 [15]. A home-made experimental equipment build at Oak Ridge National Laboratory (ORNL) was used for MG oxidation studies $[8,16]$. Basically, the oxidation setup consists of a three-zone vertical tube furnace and an analytical balance with weight-below port feature on the top of the furnace. The graphite specimen is suspended by a Pt wire in the central zone, of uniform temperature, of the furnace. The weight loss caused by oxidation is automatically recorded by computer in isothermal conditions. The oxidation temperatures at 500, 550, 600, 650, 700, 750, 800, 860, 900, and $950^{\circ} \mathrm{C}$ were selected and at each temperature 2 or 3 specimens were oxidized to around $15 \%$ weight loss with the air flow rate of $10 \mathrm{~L} / \mathrm{min}$ to test repeatability. According to the ASTM D7542-09, the oxidation rate at a given temperature is determined by a linear fit of the weight loss plotted against time in the range from $5 \%$ to $10 \%$ loss of original specimen weight. The activation energy $\left(E_{a}\right)$ and preexponential factor are calculated from the slope and intercept of the linear Arrhenius plot of the logarithm of oxidation rate versus the reciprocal of absolute temperature $[15,16]$.

2.3. Testing of Compressive Strength. In order to reveal the effect of oxidation on the mechanical properties of MG, the compressive strengths of the specimens oxidized at two typical temperatures were tested. The two selected temperatures are $550^{\circ} \mathrm{C}$ located in the kinetic regime and $900^{\circ} \mathrm{C}$ in the boundary layer control regime, respectively. For comparison, the compressive strengths of pristine (unoxidized) MG specimens were measured as well. Because the MG specimens oxidized at $550^{\circ} \mathrm{C}$ to around $15 \%$ weight loss were too weak to be handled in the strength test, specimens were oxidized to approximately $10 \%$ weight loss before the compressive strength test. Three specimens were tested for each oxidation condition. An Instron Model 1322 Electromechanical Test System was used for performing the compressive strength tests. An MTS servohydraulic machine with a $25 \mathrm{kN}$ load cell and a 407 controller was used for performing the compressive strength test at a crosshead speed of $0.00762 \mathrm{~mm} / \mathrm{s}$ using LabView program. Irregular fracture behavior of the oxidized specimens may be caused by uncontrolled failure under compression of the oxidized layer at the contact surface between the parallel faces of the cylindrical specimen and the 


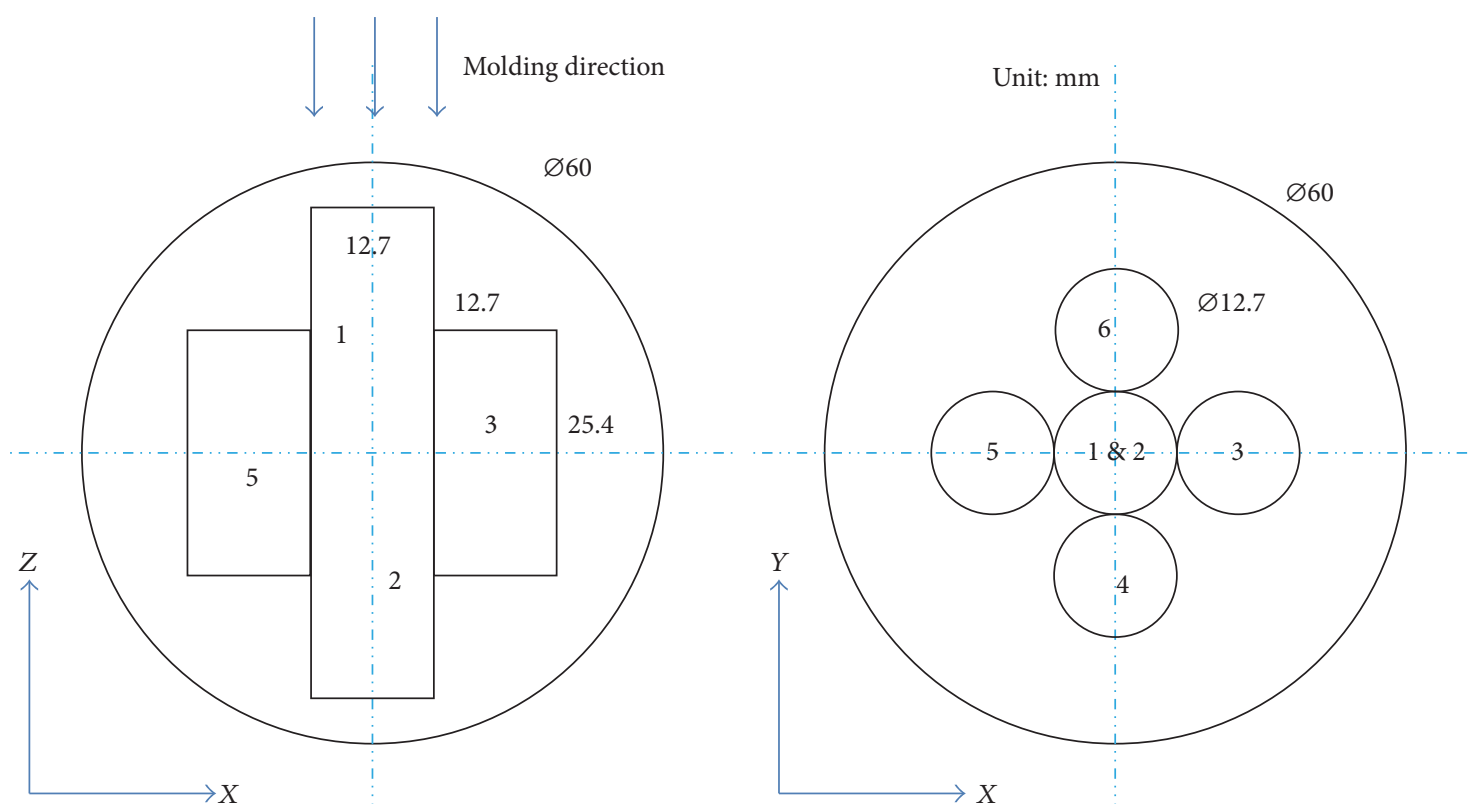

FIGURE 1: Schematic for the machining of specimens from a MG pebble.

loading fixtures. In order to avoid the uncontrolled failure, a $1 \mathrm{~mm}$ thick layer of oxidized layer was machined from both parallel faces of all the oxidized cylindrical specimens, and this surface preparation process does not reduce the strength according to literature reported results [8].

2.4. Microstructure Characterizations. The MG specimens (both oxidized and pristine) were cut at $1 / 3$ of the length for scanning microscopy examination and test of Mercury porosimetry. The shorter pieces were encased in resin and then the exposed surface after cutting was polished using several different grades of alumina powder (from coarse to fine) that allows for an optically flat surface. The microstructure of MG specimens was investigated at 1500x magnification by Hitachi S-3000N Scanning Electron Microscope (SEM) system. The larger pieces were used in the Mercury Porosimetry to measure the porosity of MG. The volume of the pores in MG was determined by measuring the volume of mercury intruding the MG at various pressures. The value of the parameters applied in the Mercury Porosimetry measurement is as follows: the surface tension of the mercury $(\gamma)$ is 485 dynes $/ \mathrm{cm}$ and the contact angle between mercury and MG $(\theta)$ is $130.0^{\circ}$, respectively.

\section{Results and Discussions}

The relationships between the residual weight and oxidation time of MG at different temperatures in air were shown in Figure 2. It can be seen that the oxidizing temperature has a remarkable influence on the oxidation of MG. The oxidation rate accelerates significantly with the increasing temperature when the oxidizing temperatures are below $800^{\circ} \mathrm{C}$. At $500^{\circ} \mathrm{C}$, it takes more than 200 hours to reach the weight loss of $15 \%$. When the oxidizing temperatures are $700^{\circ} \mathrm{C}$ and $900^{\circ} \mathrm{C}$, the oxidation time for $15 \%$ weight loss is 0.9 and 0.2 hours,

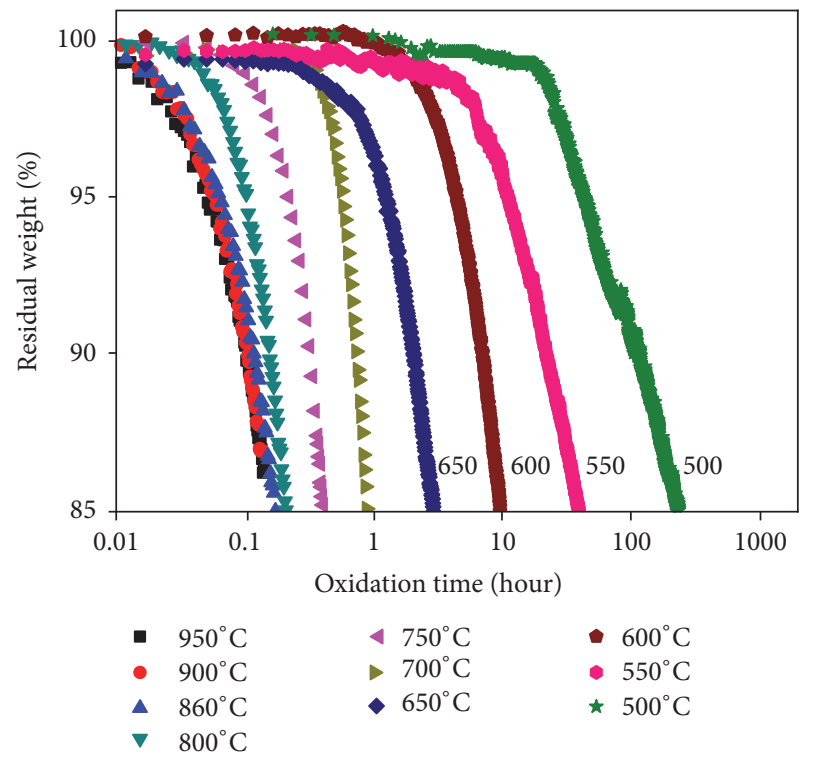

FIGURE 2: The relationship between the weight loss and oxidation time at different temperatures.

respectively. The average oxidation rate of $\mathrm{MG}$ at $900^{\circ} \mathrm{C}$ is more than 1000 times faster than that at $500^{\circ} \mathrm{C}$. However, with further increases in oxidizing temperature above $800^{\circ} \mathrm{C}$, the oxidation rates remain almost constant, showing that the oxidation control mechanisms at relatively low and high oxidizing temperatures are different.

Based on the average oxidation rate in the range from $5 \%$ to $10 \%$ loss of original specimen weight, the Arrhenius plot of $M G$ in the temperature range of $500-950^{\circ} \mathrm{C}$ is shown in Figure 3. The slopes and intercepts of the best-fit lines for three regimes were presented in Figure 3 as well. The 


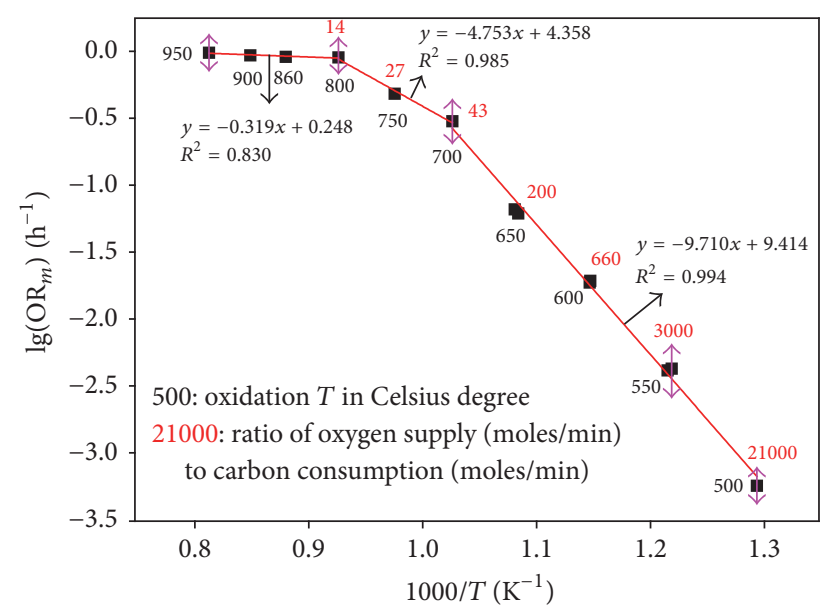

Figure 3: Arrhenius plot of MG oxidized in air at $500-950^{\circ} \mathrm{C}$.

procedure recommended in ASTM D7542-09 was adopted to calculate the $E_{a}$ for each regime from the Arrhenius plot. The $E_{a}$ of MG was determined to be $185.83 \mathrm{~kJ} / \mathrm{mol}$ in the chemical kinetics control regime, Regime I, at temperatures below $700^{\circ} \mathrm{C} ; 90.96 \mathrm{~kJ} / \mathrm{mol}$ in the in-pore controlled diffusion regime, Regime II, from 700 to $800^{\circ} \mathrm{C}$; and $6.10 \mathrm{~kJ} / \mathrm{mol}$ in the boundary layer control regime, Regime III, from 800 to $950^{\circ} \mathrm{C}$. The $E_{a}$ in Regime II is around one-half of that in Regime I and $E_{a}$ in Regime III is very close to zero, in good agreement with the $E_{a}$ variation trend in the three regimes mentioned elsewhere [11]. As the $E_{a}$ for most graphite materials was in the range of $190-210 \mathrm{~kJ} / \mathrm{mol}$ [11], the slightly smaller $E_{a}$ for $M G$ was probably due to the existence of incompletely graphitized binder in the MG. The mass-normalized oxidation rate $\left(\mathrm{OR}_{m}\right)$ for MG in Regime I can be described as

$$
\mathrm{OR}_{m}=2.59 \times 10^{9} \times \exp \left(\frac{-22362.13}{T}\right) \mathrm{h}^{-1},
$$

where $T$ is the temperature in Kelvin units.

The ratio of oxygen supply rate (moles/min) to carbon loss rate (moles/min) at relatively low temperatures is also shown in Figure 3. A previous report suggested that Arrhenius plots of standard size specimens (diameter $=$ length $=$ $25.4 \mathrm{~mm}$ ) were linear as long as this ratio was larger than $\sim 10$, indicating oxidation in Regime I [11]. For the MG specimens with the diameter of $12.7 \mathrm{~mm}$, the plot was linear between 500 and $700^{\circ} \mathrm{C}$. As the oxidation rate increased with the increase in temperature and the ratio declined gradually. When the ratio dropped to $\sim 43$ at $700^{\circ} \mathrm{C}$, the plot started to bend, which apparently does not agree with the rule mentioned above. However, considering that the oxidation is uniform throughout the graphite specimens in Regime I and the MG specimens have only $1 / 4$ mass of the standard specimens, the carbon loss rate should be four times larger than the currently observed rate if the standard size specimens were used with the same air flow rate of $10 \mathrm{~L} / \mathrm{min}$. Accordingly, the ratio should be reduced four times, from 43 to 11.75 , which is very close to the empirically estimated threshold ratio of $\sim 10$.

The average dimensional and corresponding density changes of specimens oxidized to $\sim 10 \%$ weight loss at 550 and

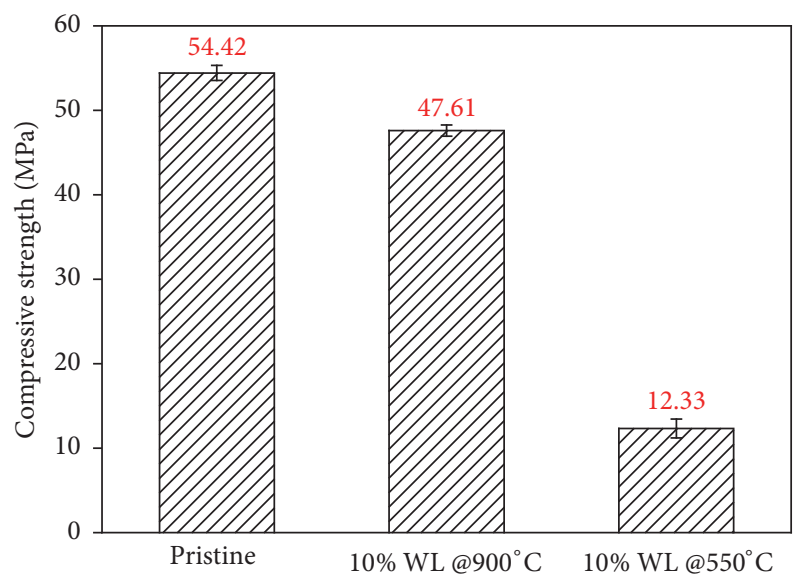

FIGURE 4: Average values for compressive strength of MG specimens oxidized to $\sim 10 \%$ weight loss at 550 and $900^{\circ} \mathrm{C}$.

$900^{\circ} \mathrm{C}$ for compressive strength testing are shown in Table 2 . The dimension did not change (within the experimental errors) after oxidation at $550^{\circ} \mathrm{C}$. However, the length and diameter of specimens oxidized at $900^{\circ} \mathrm{C}$ shrank by $1.3 \%$ and $3.2 \%$, respectively. As a result, the average density of the specimens oxidized at 550 and $900^{\circ} \mathrm{C}$ declined by $10.8 \%$ and $3.45 \%$, respectively, showing the effect of different oxidation regimes. When the specimens were oxidized at $550^{\circ} \mathrm{C}$ (in Regime I) the oxidation was uniform throughout the specimens, which slightly changed their size but significantly decreased their density. When the oxidation temperature increased to $900^{\circ} \mathrm{C}$ (in Regime III), oxidation occurred mainly on the surface, which changed the dimensions but had only slight influence on the density.

Figure 4 indicates the average values of compressive strength for MG specimens oxidized to $\sim 10 \%$ weight loss at 550 and $900^{\circ} \mathrm{C}$. With the comparative weight loss of $\sim 10 \%$, the compressive strength of the specimens oxidized at $900^{\circ} \mathrm{C}$ is about four times larger than of those oxidized at $550^{\circ} \mathrm{C}$. Comparing with the strength of pristine specimens, the reduction in compressive strength is $77.3 \%$ after oxidation at $550^{\circ} \mathrm{C}$ in the kinetic regime and only $12.5 \%$ for oxidation at $900^{\circ} \mathrm{C}$. The average rate of strength loss for oxidation at $550^{\circ} \mathrm{C}$ is $7.63 \%$ of the initial compressive strength value per each percentage of weight loss. Meanwhile, after oxidation at $900^{\circ} \mathrm{C}$ the figure is only $1.17 \%$ of initial strength value for every $1 \%$ of weight loss. It is obvious that oxidation at $550^{\circ} \mathrm{C}$ causes more degradations to compressive strength of MG than oxidation at $900^{\circ} \mathrm{C}$. Figures 5-7 show the SEM images of the pristine $M G$ and MG specimens oxidized at $550^{\circ} \mathrm{C}$ and $900^{\circ} \mathrm{C}$ in air to about $10 \%$ weight loss. Table 3 reports the value of porosity for MG specimens and corresponding oxidation conditions. From Figures 5 and 7, it can be seen that the microstructure difference between the pristine MG and MG specimens oxidized at $900^{\circ} \mathrm{C}$ is too insignificant to be observed by eye. As shown in Table 3, the porosity of MG specimens oxidized at $900^{\circ} \mathrm{C}$ is slightly lower than that of the pristine $\mathrm{MG}$, which is in good agreement with the SEM investigation results. However, as shown in Figure 6, the microstructure of MG specimens oxidized at $550^{\circ} \mathrm{C}$ dramatically changed after the oxidation 
TABLE 2: Average physical property changes before and after oxidation to around $10 \%$ weight loss.

\begin{tabular}{|c|c|c|c|c|c|c|c|c|}
\hline \multirow{2}{*}{ Oxidation $T\left({ }^{\circ} \mathrm{C}\right)$} & \multicolumn{2}{|c|}{ Weight loss (\%) } & \multicolumn{2}{|c|}{ Length (\%) } & \multicolumn{2}{|c|}{ Diameter (\%) } & \multicolumn{2}{|c|}{ Density (\%) } \\
\hline & Average & St. dev. & Average & St. dev. & Average & St. dev. & Average & St. dev. \\
\hline 550 & -10.13 & 0.35 & +0.35 & 0.02 & +0.20 & 0.01 & -10.79 & 0.28 \\
\hline 900 & -10.73 & 0.51 & -1.29 & 0.03 & -3.22 & 0.05 & -3.45 & 0.12 \\
\hline
\end{tabular}

TABle 3: Porosity of MG specimens (both pristine and oxidized) measured by Mercury Porosimetry.

\begin{tabular}{lc}
\hline Samples & Porosity (\%) \\
\hline Pristine & 18.09 \\
Oxidized at $550^{\circ} \mathrm{C}$ to $10 \% \mathrm{WL}$ & 30.87 \\
Oxidized at $900^{\circ} \mathrm{C}$ to $10 \% \mathrm{WL}$ & 19.74 \\
\hline
\end{tabular}

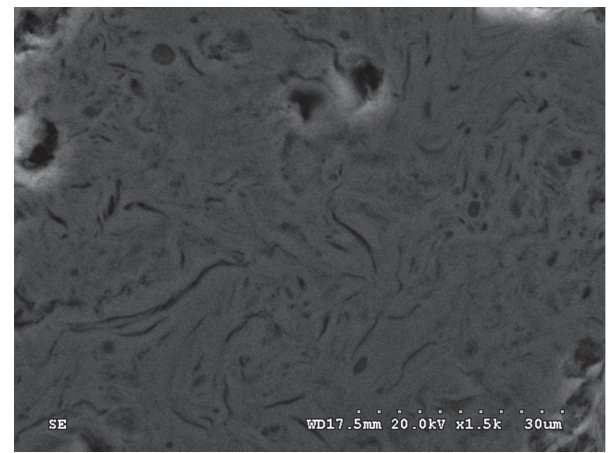

FIGURE 5: SEM image of pristine A3-3 MG at 1500x Mag.

where a large amount of pores were developed and formed. Its porosity value increases remarkably from $18.09 \%$ of the porosity of pristine MG to $30.87 \%$. The different development and formation of pores between the specimens oxidized at 550 and $900^{\circ} \mathrm{C}$ are due to the different oxidation mechanism: oxidation at $550^{\circ} \mathrm{C}$ in the kinetic regime spreads uniformly in the bulk, while oxidation at $900^{\circ} \mathrm{C}$ in the boundary layer control regime is limited to a narrow surface layer and bulk is not apparently affected. Comparing with the microstructure of the pristine MG shown in Figure 5, the binder material of the MG specimens oxidized at $550^{\circ} \mathrm{C}$ in Figure 6 shrinks or even disappears around the filler grains, which indicates the weaker oxidation resistance of the binder phase [10]. In a previous report, it was found that the compressive strength of PCEA graphite oxidized at $600^{\circ} \mathrm{C}$ in the kinetic regime to around $10 \%$ weight loss, dropping only by $\sim 26 \%$ [8]. From the microstructure images and porosity measurement results, it can be concluded that the significant strength loss of the MG specimens oxidized at $550^{\circ} \mathrm{C}$ in the kinetic regime may be ascribed to both the pore formation throughout the bulk after oxidation and the preferential binder phase oxidation.

\section{Conclusion}

Oxidation behavior of MG in air in the temperature range from 500 to $950^{\circ} \mathrm{C}$ was investigated. The activation energy

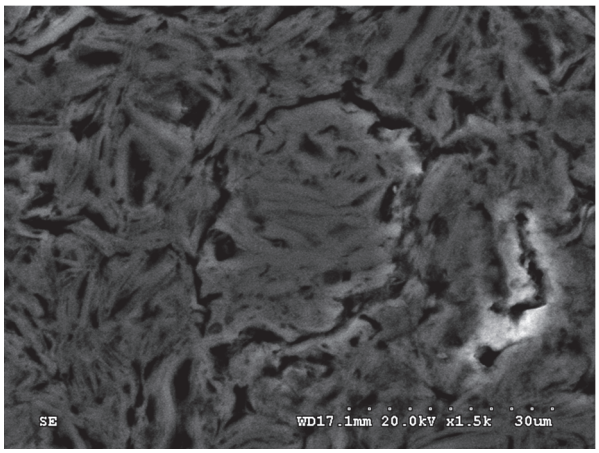

FIgURE 6: SEM image of A3-3 MG oxidized at $550^{\circ} \mathrm{C}$ to $10 \%$ weight loss at 1500x Mag.

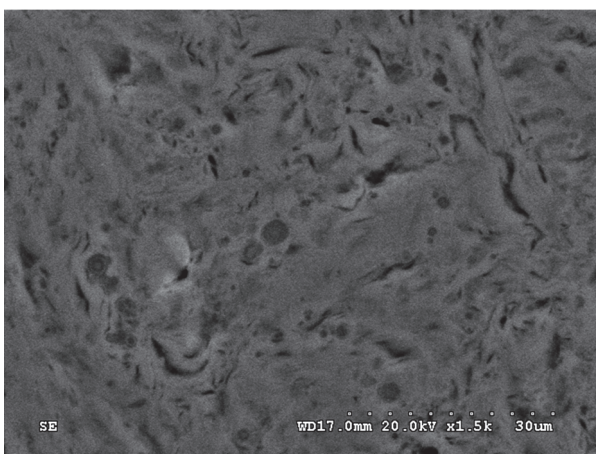

Figure 7: SEM image of A3-3 MG oxidized at $900^{\circ} \mathrm{C}$ to $10 \%$ weight loss at 1500x Mag.

in the chemical kinetic control regime calculated from the Arrhenius plot was $\sim 185 \mathrm{~kJ} / \mathrm{mol}$, slightly lower than that of nuclear graphite, which indicates that MG was more vulnerable to oxidation. Oxidizing temperature also played an important role in the degradation of compressive strength of MG. Oxidation at $900^{\circ} \mathrm{C}$ caused less damage on the compressive strength than oxidation at $550^{\circ} \mathrm{C}$. At the same weight loss of $\sim 10 \%$, the compressive strength of specimens oxidized at $900^{\circ} \mathrm{C}$ was about 4 times larger than after oxidation at $550^{\circ} \mathrm{C}$. The average rates of strength loss for oxidation at $550^{\circ} \mathrm{C}$ and $900^{\circ} \mathrm{C}$ are $7.63 \%$ and $1.17 \%$ of the initial compressive strength value for every $1 \%$ of weight loss, respectively. The significant strength loss of MG induced by the oxidation at $550^{\circ} \mathrm{C}$ in the kinetic regime was probably due to both the uniform pores formation throughout the bulk of $\mathrm{MG}$ and the preferential oxidation of binder phase. This conclusion was supported by the measurements on the compressive strength and rationalized by the SEM examinations and porosity measurements of the pristine and oxidized MG specimens. 


\section{Disclosure}

This manuscript has been authored by UT-Battelle, LLC under Contract no. DE-AC05-00OR22725, with the U.S. Department of Energy. The United States Government retains and the publisher, by accepting the article for publication, acknowledges that the United States Government retains a nonexclusive, paid-up, irrevocable, worldwide license to publish or reproduce the published form of this manuscript, or allow others to do so, for United States Government purposes. The Department of Energy will provide public access to these results of federally sponsored research in accordance with the DOE Public Access Plan (https://energy.gov/downloads/ doe-public-access-plan).

\section{Conflicts of Interest}

The authors declare that they have no conflicts of interest.

\section{Acknowledgments}

Supports from the State Scholarship Foundation of China (201406215002), the Chinese National S\&T Major Project (ZX06901), Chinese National Natural Science Foundation (51420105006), and Key Program for International S\&T Cooperation Projects of China (2016YFE0100700) are acknowledged. The work performed at Oak Ridge National Laboratory was supported partially by the Advanced Reactor Technologies program of U.S. Department of Energy, Office of Nuclear Energy.

\section{References}

[1] T. L. Albers, "High-temperature properties of nuclear graphite," Journal of Engineering for Gas Turbines and Power, vol. 131, no. 6, Article ID 064501, pp. 1-2, 2009.

[2] Z. Zhang, Z. Wu, D. Wang et al., "Current status and technical description of Chinese $2 \times 250$ MWth HTR-PM demonstration plant," Nuclear Engineering and Design, vol. 239, no. 7, pp. 12121219, 2009.

[3] Z. Xiangwen, L. Zhenming, Z. Jie et al., "Preparation of spherical fuel elements for HTR-PM in INET," Nuclear Engineering and Design, vol. 263, pp. 456-461, 2013.

[4] W.-K. Choi, B.-J. Kim, E.-S. Kim, S.-H. Chi, and S.-J. Park, "Oxidation behavior of IG and NBG nuclear graphites," Nuclear Engineering and Design, vol. 241, no. 1, pp. 82-87, 2011.

[5] C. I. Contescu, T. Guldan, R. P. Wichner, and T. D. Burchell, Oxidation resistance of NGNP graphite materials, NGNP program, Oak Ridge, TN, USA, 2008.

[6] S. Chi and G. Chan Kim, "Effects of air flow rate on the oxidation of NBG-18 and NBG-25 nuclear graphite," Journal of Nuclear Materials, vol. 491, pp. 37-42, 2017.

[7] X. Luo, J.-C. Robin, and S. Yu, "Comparison of oxidation behaviors of different grades of nuclear graphite," Nuclear Science and Engineering, vol. 151, no. 1, pp. 121-127, 2005.

[8] C. I. Contescu, Effect of air oxidation on pore structure development and mechanical properties of nuclear graphite, Oak Ridge, TN, USA, 2010.

[9] R. Moormann, H.-K. Hinssen, and K. Kühn, "Oxidation behaviour of an HTR fuel element matrix graphite in oxygen compared to a standard nuclear graphite," Nuclear Engineering and Design, vol. 227, no. 3, pp. 281-284, 2004.

[10] J. J. Lee, T. K. Ghosh, and S. K. Loyalka, "Oxidation rate of graphitic matrix material in the kinetic regime for VHTR air ingress accident scenarios," Journal of Nuclear Materials, vol. 451, no. 1-3, pp. 48-54, 2014.

[11] C. I. Contescu, S. Azad, D. Miller, M. J. Lance, F. S. Baker, and T. D. Burchell, "Practical aspects for characterizing air oxidation of graphite," Journal of Nuclear Materials, vol. 381, no. 1-2, pp. 15-24, 2008.

[12] H.-K. Hinssen, K. Kühn, R. Moormann, B. Schlögl, M. Fechter, and M. Mitchell, "Oxidation experiments and theoretical examinations on graphite materials relevant for the PBMR," Nuclear Engineering and Design, vol. 238, no. 11, pp. 3018-3025, 2008.

[13] R. P. Wichner, T. D. Burchell, and C. I. Contescu, "Penetration depth and transient oxidation of graphite by oxygen and water vapor," Journal of Nuclear Materials, vol. 393, no. 3, pp. 518-521, 2009.

[14] "Standard test method for compressive strength of carbon and graphite. ASTM C695-91," 2010.

[15] "Standard test method for air oxidation of carbon and graphite in the kinetic regime. ASTM D7542-09".

[16] C. I. Contescu and T. D. Burchell, ASTM activities on standard method for graphite oxidation. ORNL/GEN4/LTR-09-002, Oak Ridge, TN, USA, 2009. 


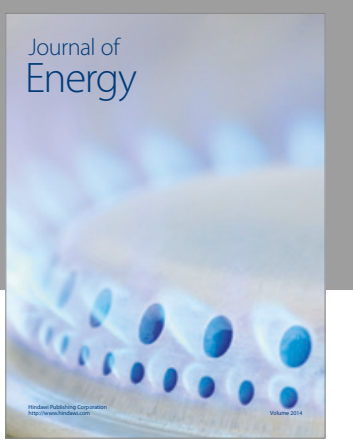

Journal of

Industrial Engineering
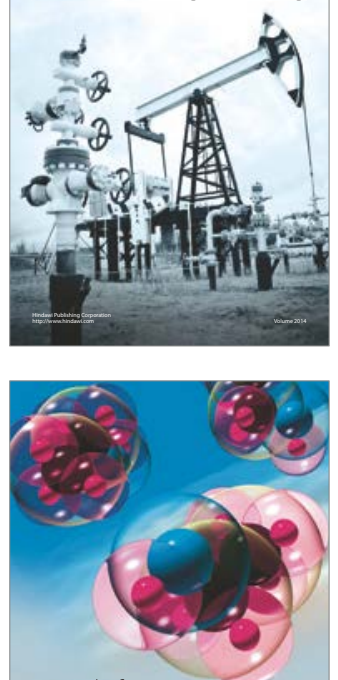

Fuels
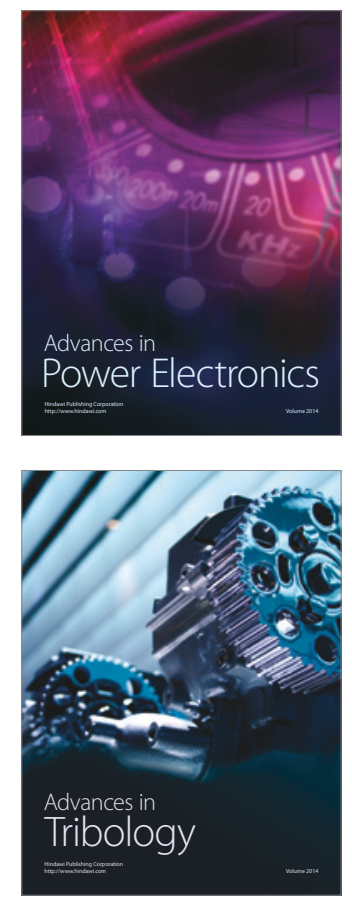
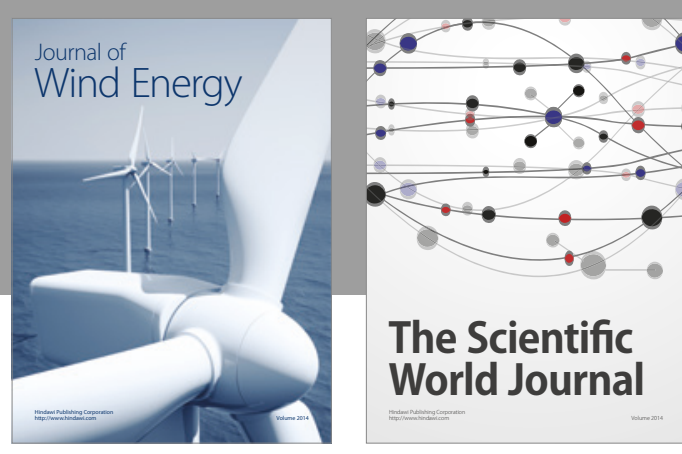

The Scientific World Journal
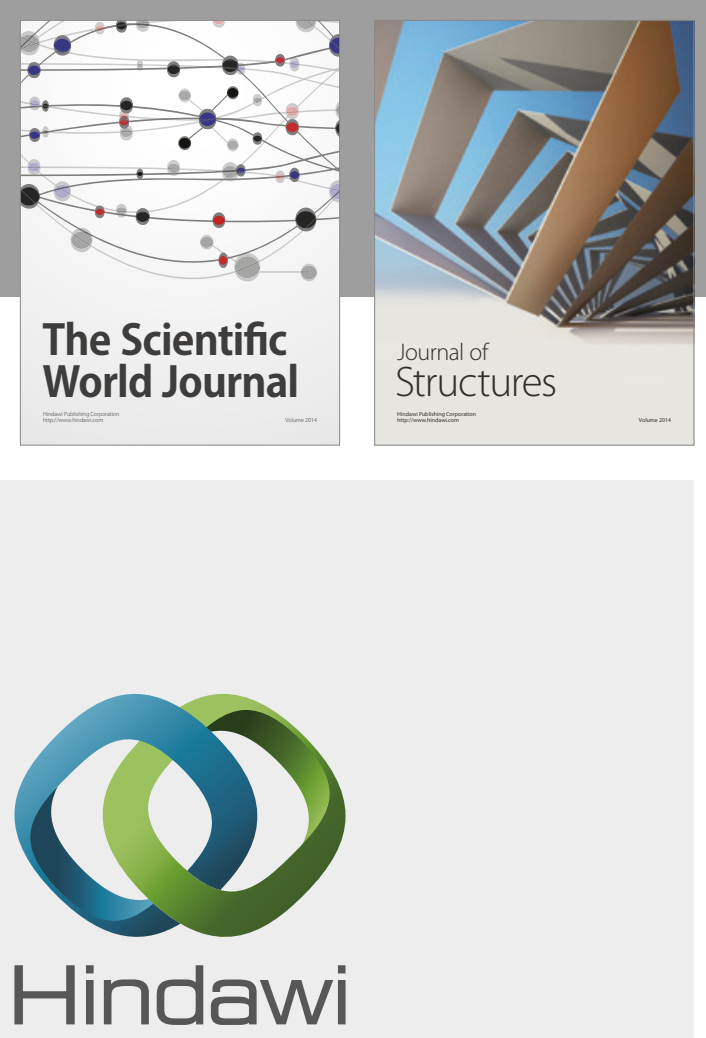

Submit your manuscripts at

https://www.hindawi.com
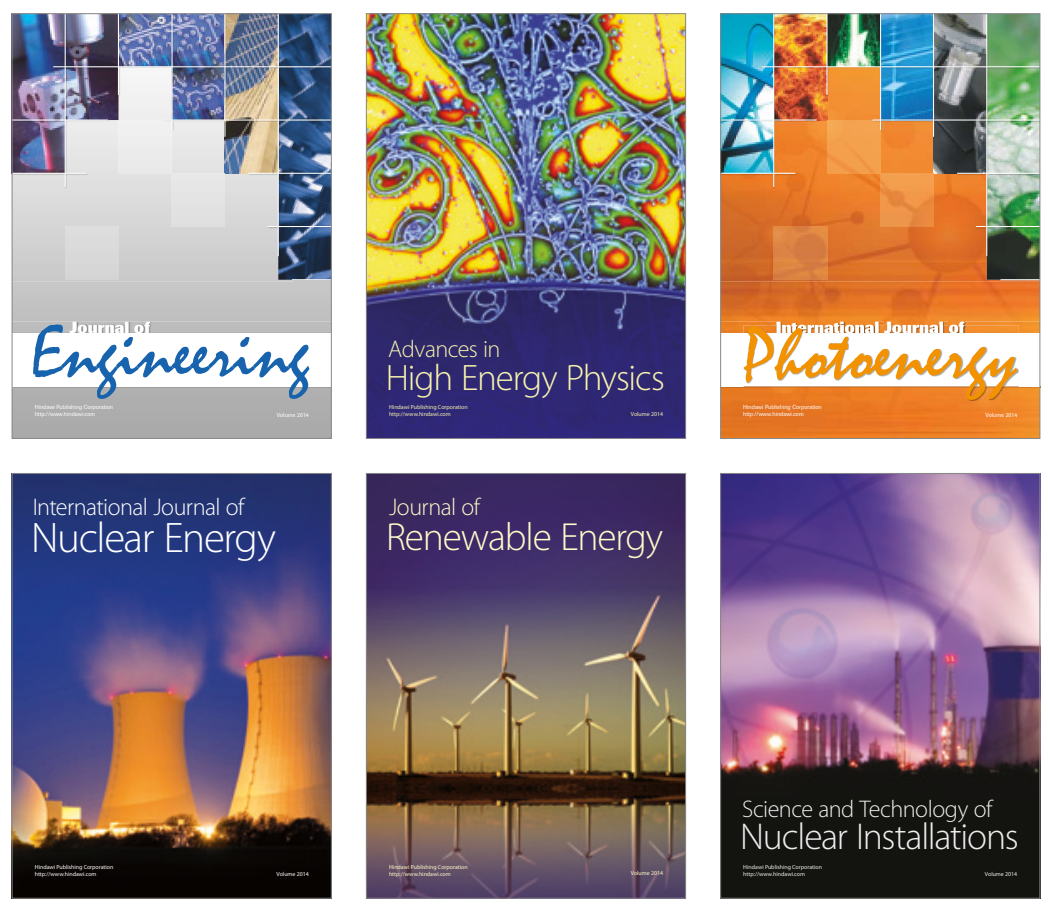

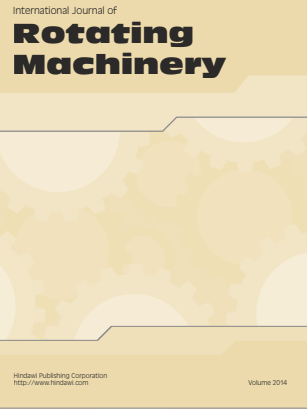

Journal of

Petroleum Engineering

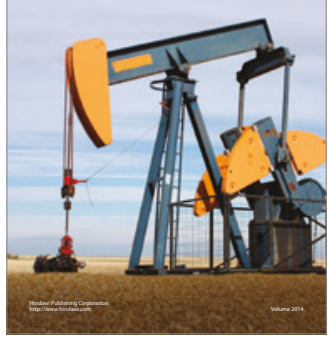

Journal of
Solar Energy
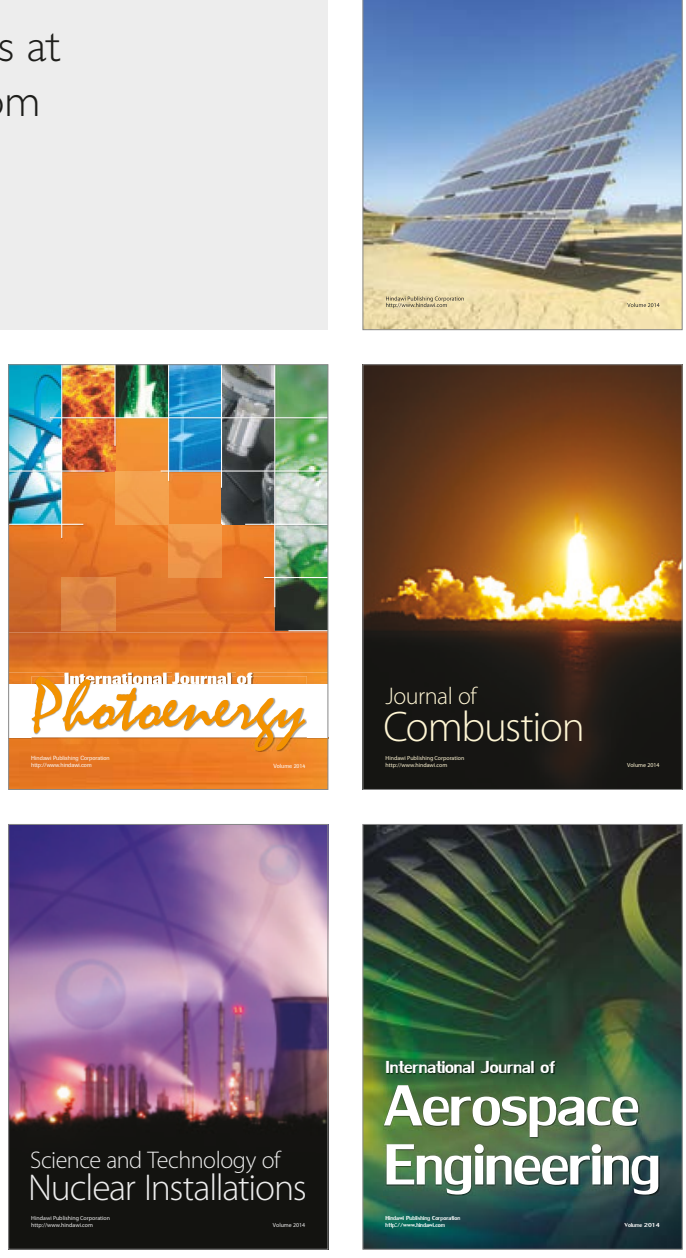